\title{
Multilevel modelling of sociodemographic predictors of various levels of anaemia among women in Mali
}

\author{
Ismael Ngnie-Teta ${ }^{1, *}$, Barthelemy Kuate-Defo ${ }^{2}$ and Olivier Receveur ${ }^{3}$ \\ ${ }^{1}$ Micronutrient Initiative, 180 Elgin Street - Suite 1000, Ottawa, Ontario, Canada K2P 2K3: ${ }^{2}$ Département de \\ Démographie, Université de Montréal, Montréal, Québec, Canada: ${ }^{3}$ Département de Nutrition, Faculté de \\ Médecine, Université de Montréal, Montréal, Québec, Canada
}

Submitted 17 March 2008: Accepted 4 November 2008: First published online 24 December 2008

\begin{abstract}
Objective: Anaemia currently affects $40-80 \%$ of women in Africa. While risk factors for anaemia have been intensively studied, research has rarely compared risk factors between mild anaemia and moderate/severe anaemia. Also, the contribution of neighbourhood to the prevalence of anaemia has been rarely studied. The aim of the present study was to identify and compare individual and contextual factors associated with various levels of anaemia among women.

Design: A multilevel analysis of data from the 2001 Mali Demographic and Health Survey ( $n$ 3763) was carried out. Outcomes variables were mild anaemia, moderate-to-severe anaemia and any anaemia. Multilevel regression analyses were performed for each outcome.

Setting: Mali, West Africa.

Subjects: Women ( $n$ 3763) aged 15 to 49 years, including 512 pregnant women. Results: Among the eleven potential risk factors included in the models, two factors were associated with mild anaemia (BMI and education), three with any anaemia (pregnancy, BMI and education) and six with moderate-to-severe anaemia (pregnancy, BMI, education, wealth, childhood residency and region of residence). Clustering of anaemia within communities was $20 \%$ for moderateto-severe anaemia and 13\% for mild anaemia. Despite significant differences in the prevalence of anaemia across regions in Mali, no difference between regions in the risk of mild anaemia was found and only the region of Gao showed a significantly higher risk of moderate-to-severe anaemia.

Conclusions: The findings indicate that sociodemographic risk factors as well as clustering of anaemia varies with the severity of anaemia. Specific studies are needed to identify risk factors of mild anaemia as well as its consequences, as mild anaemia accounts for $20-40 \%$ of total prevalence of anaemia in Africa.
\end{abstract}

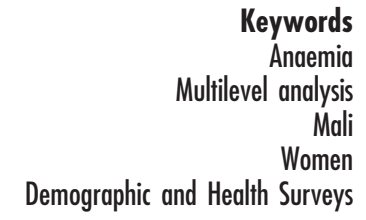

Anaemia represents a major public health problem among women of reproductive age in developing countries. A recent review suggested that $41 \%$ of women in Africa are anaemic ${ }^{(1)}$. The consequences of anaemia for women include increased risk of maternal morbidity and mortality, and lower productivity ${ }^{(2-6)}$.

Maternal anaemia is also associated with a higher risk for low birth weight, premature birth, perinatal and neonatal death, as well as inadequate Fe stores for the newborn $^{(7,8)}$. It is estimated that, each year, 271000 deaths and 10140000 disability-adjusted life years are attributable to Fe-deficiency anaemia in Africa ${ }^{(1)}$.

Common causes of anaemia among women in Mali, as identified in the literature, include micronutrient deficiencies, infections (largely malaria), pregnancy and poor socio-economic conditions ${ }^{(9-15)}$. However, little research has been done to identify the risk factors for different levels of anaemia (mild, moderate or severe). Also, the multilevel analysis technique has rarely been used in nutritional epidemiology to investigate the clustering of anaemia within communities.

The purpose of the present study is to identify, compare and discuss the risk factors of varying levels of anaemia (mild, moderate-to-severe and any) among Malian women. The study also attempts to separate and quantify the contribution of community characteristics $v$. individual characteristics to the prevalence of anaemia in Malian women.

\section{Materials and methods}

\section{Data and study population}

The study is based on secondary analysis of data from the Demographic and Health Survey (DHS) carried out in 
2001 in Mali. The Mali DHS is a nationally representative survey including 3763 Malian women aged 15-49 years nested in a sample of 403 clusters (communities). The sample design involved a probabilistic two-stage sampling. In the first stage, enumeration areas were randomly selected with equal probability. The second stage involved interviewing eligible households and individual respondents. The detailed sampling methodology is presented in the DHS sampling manual ${ }^{(16)}$ and DHS country reports ${ }^{(17)}$.

The survey consisted of individual and household questionnaires addressed to women of reproductive age (15-49 years). The individual questionnaire gathered information on the background characteristics of survey respondents. The household questionnaire collected comparable information on household composition, including relationship to head of the household, age and sex of all household members, and educational attainment for those aged 6 years and above.

\section{Outcome measures}

$\mathrm{Hb}$ levels were measured in capillary blood using the HemoCue. For the Mali DHS, Hb measurements were not repeated; however, the precision and accuracy of the HemoCue system is known to be very high (concordance coefficients of 0.99 and 0.98 and CV less than $1 \%$ ). High within-subject variability of capillary blood samples has, however, been reported in some studies ${ }^{(18,19)}$. DHS experience has shown that this individual variability in test results is highly related to the tester's skills; DHS surveys therefore use intensive standardized training under the close supervision of a skilled phlebotomist to significantly improve the capillary sampling technique and reduce within-subject variability. Detailed procedures are explained elsewhere ${ }^{(20)}$. Anaemia cut-off points used in the present study were those recommended by WHO for women and pregnant women ${ }^{(21-23)}$. Any anaemia was defined as $\mathrm{Hb}$ lower than $12.0 \mathrm{~g} / \mathrm{dl}$ in non-pregnant women and $\mathrm{Hb}$ lower than $11.0 \mathrm{~g} / \mathrm{dl}$ in pregnant women. Mild anaemia was defined as $\mathrm{Hb}$ level between $10 \cdot 0$ and $11.9 \mathrm{~g} / \mathrm{dl}$ among non-pregnant women and between $10 \cdot 0$ and $10.9 \mathrm{~g} / \mathrm{dl}$ among pregnant women. Moderateto-severe anaemia was defined as $\mathrm{Hb}$ lower than $10 \cdot 0 \mathrm{~g} / \mathrm{dl}$ in both non-pregnant and pregnant women.

\section{Exposure measures}

Potential risk factors for anaemia among women included in the analysis were: pregnancy (non-pregnant, pregnant); age (15-24, 25-34, 35-49 years); BMI $(<18 \cdot 5$, $18.5-25,>25 \mathrm{~kg} / \mathrm{m}^{2}$ ); bed net use (yes, no); household size ( $1-4,5-7,>7$ persons); education (no education, any education); husband's education (no education, any education); wealth index (low, medium, high). The wealth index is a composite measure of the cumulative living standard of a household used as a proxy for socioeconomic status (SES). It was calculated using easyto-collect data on a household's ownership of selected assets, such as televisions and bicycles, materials used for housing construction and types of water access and sanitation facilities. The most important householdowned durable goods were identified and placed on a continuous scale by principal components analysis. In total, 162 indicators collected in eighty-one countries were used by ORC Macro to build the wealth index. For tabular analysis with the DHS wealth index, we have used percentiles (quintiles). The lowest two quintiles were considered as low wealth index, quintiles three and four as medium wealth index and the highest quintile as high wealth index. The DHS wealth index procedure is detailed elsewhere ${ }^{(24)}$. Community-level variables included in the analysis were childhood place of residence (urban, rural), current place of residence (urban, rural) and region of residence (province).

\section{Statistical methods}

Data analysis was performed using multilevel modelling procedures. Multilevel regression analysis is a powerful statistical modelling method that allows the incorporation of explanatory variables at different levels of the hierarchy so that household- and community-level clustering of the outcome are taken into account. It also produces estimates of logistic regression coefficients, standard errors, confidence intervals and significance tests that are generally more conservative than those obtained from simple logistic regression models ${ }^{(25-29)}$. Four multilevel logistic regression models were applied to the data to examine their associations to different levels of anaemia using the subset of respondents with full information ( $n$ 2585). The first model was the null model with no explanatory variable. The second model included women's characteristics (pregnancy, age, BMI). The third model added SES variables (household size, woman's education, husband's education, wealth index) to Model 2. The final model (full model) added the communityrelated variables (childhood place of residence, current place of residence, region) to Model 2. Each of the four models was built for mild anaemia, moderate-to-severe anaemia and any anaemia as outcomes.

For each model, the $\beta$ coefficients (standard errors) were converted into odds ratios $(95 \%$ confidence intervals) and random estimates were quantified in terms of the variance partition coefficient (VPC), which is a variant of the intraclass correlation for non-linear outcomes $^{(15,25,29-31)}$. The VPC gives an estimation of the clustering of anaemia in communities and is interpreted as the percentage of total variance in risk of anaemia attributable to community clustering of anaemia at the neighbourhood level. A high VPC would reflect a high clustering of anaemia prevalence within communities and a high neighbourhood effect on individual risk of anaemia. Multilevel logistic parameters were estimated using restricted iterative generalized least squares (RIGLS) and penalized quasi likelihood (PLQ) ${ }^{(15,25,31)}$. The multilevel 
logistic regression models were fitted using the MLwiN software version $2 \cdot 0$ (Centre for Multilevel Modelling, University of Bristol, Bristol, UK).

\section{Limits of the study}

One limitation of the present study is its cross-sectional design. Despite the rigorous selection of variables and consistency of our main results with those of other studies on anaemia, no causal inference can be made. However, the correlations observed can help us guide the development and implementation of anaemia intervention policies. Another limitation of the study was the absence of data on dietary Fe intake and supplementation in the DHS surveys. It is, however, already well documented that Fe-deficiency anaemia contributes approximately 50\% to total anaemia prevalence in West Africa.

\section{Etbical clearance}

The study is based on secondary analysis of existing survey data with all identifying information removed. Training for the Mali DHS survey teams included special training for the field enumerators and the team leaders on how to present the informed consent statement. The study was approved by the ORC Macro Research Ethics Committee as well as the National Ethics Committee for Mali (Bamako). Prior to the test, each woman was asked whether she would agree to participate in the study and, if so, to sign a form giving permission for blood collection. The form explained the $\mathrm{Hb}$ testing procedure and causes and consequences of anaemia. The women were assured that the results would be kept confidential.

\section{Results}

\section{Prevalence and distribution of anaemia in Malian women}

Overall, 3763 Malian women were included in the descriptive analysis of whom $512(13.6 \%)$ were pregnant. The mean Hb level was 11.3 (SD 1.7 ) g/dl in non-pregnant women and 9.9 (SD 1.6) $\mathrm{g} / \mathrm{dl}$ in pregnant women. The overall prevalence of anaemia in the women was $66 \%$. The prevalence of mild, moderate and severe anaemia was $40 \cdot 7 \%, 22 \cdot 5 \%$ and $2 \cdot 7 \%$, respectively. As shown in Table 1 , there was a substantial difference in the prevalence of anaemia between non-pregnant women (64\%) and pregnant women $(77 \%)$. These differences were more marked when anaemia was split by severity level. Pregnant women were almost two times more affected by moderate and severe anaemia (prevalence ratio of $2 \cdot 4$ and $1 \cdot 8$, respectively). Consequently, mild anaemia prevalence was higher among non-pregnant women than pregnant women. The prevalence of anaemia also varied enormously from one region of Mali to another. The lowest prevalence of anaemia was found in Bamako, the capital (54\% overall, with only $15 \%$ prevalence of moderate plus severe anaemia).
Anaemia prevalence was above $60 \%$ in all other regions, with the highest prevalence found in Mopti and Gao (>75\% overall, with $32 \%$ and $35 \%$ prevalence of moderate plus severe anaemia, respectively).

Bivariate analyses (not presented) showed that almost the same variables were associated with moderate and severe anaemia. For this reason, moderate and severe anaemia are merged into a single category named 'moderate-to-severe anaemia' $(\mathrm{Hb}<10 \cdot 0 \mathrm{~g} / \mathrm{dl})$.

\section{Demographic and socio-economic markers associated with various levels of anaemia}

Multilevel logistic regression estimates (odds ratio and confidence intervals) are presented in Table 2 . The three outcomes considered in the regression models are mild anaemia, moderate-to-severe anaemia and any anaemia. Only estimates from full models are presented.

\section{Factors associated with mild anaemia}

Two factors (education and BMI) among the eleven included in the regression models were significantly associated with mild anaemia. Overweight women (BMI $\left.>25 \mathrm{~kg} / \mathrm{m}^{2}\right)$ were less likely to be anaemic (OR $=0.73 ; 95 \%$ CI 0.57 , 0.94) than women with normal BMI and underweight women (see Table 2). Women who never attended school had a higher risk of mild anaemia than women with any education ( $\mathrm{OR}=1.31 ; 95 \%$ CI $1.02,1 \cdot 69)$. These two variables were also significantly associated with moderateto-severe anaemia as well as any anaemia.

Factors associated with moderate-to-severe anaemia In addition to the two variables associated with mild anaemia, four more variables were significantly associated with moderate-to-severe anaemia. For BMI, risk of moderate-to-severe anaemia was significantly higher among women with $\mathrm{BMI}<18.5 \mathrm{~kg} / \mathrm{m}^{2}(\mathrm{OR}=1 \cdot 58 ; 95 \%$ CI $1 \cdot 14,2 \cdot 19)$ and significantly lower among overweight women $(\mathrm{OR}=0 \cdot 64 ; 95 \% \mathrm{CI} 0 \cdot 47,0 \cdot 89)$ compared with women with normal BMI. Pregnancy, which is one of the most obvious risk factors for anaemia, was associated with moderate-to-severe anaemia $(\mathrm{OR}=3 \cdot 75$; $95 \% \mathrm{CI}$ $2 \cdot 85,4 \cdot 95)$ but not with mild anaemia.

Women from households with medium wealth index had higher prevalence of moderate-to-severe anaemia than those from wealthier households (OR $=1 \cdot 46 ; 95 \%$ CI 1.08, 1.97), but no significant difference was observed when the outcome was mild anaemia or any anaemia.

Similarly, childhood place of residence was associated with moderate-to-severe anaemia but not with mild anaemia or any anaemia. Women who spent their childhood in rural settings were more likely to be moderatelyto-severely anaemic than their counterparts from towns ( $\mathrm{OR}=1 \cdot 74 ; 95 \% \mathrm{CI} 1 \cdot 27,2 \cdot 38)$. The region of residence was also associated with moderate-to-severe anaemia but not mild anaemia. In particular, women living in the region of Gao had the highest risk of anaemia compared 
Table 1 Prevalence of varying levels of anaemia in Malian women aged 15-49 years according to selected explanatory variables considered for analytical multilevel models: data from the 2001 Mali Demographic and Health Survey

\begin{tabular}{|c|c|c|c|c|c|}
\hline Characteristic & $n$ & Any anaemia (\%) & Mild anaemia (\%) & Moderate anaemia (\%) & Severe anaemia (\%) \\
\hline \multicolumn{6}{|l|}{ Pregnancy } \\
\hline Yes & 512 & $76 \cdot 6$ & $26 \cdot 2$ & $46 \cdot 1$ & $4 \cdot 3$ \\
\hline No & 3251 & $64 \cdot 2$ & $43 \cdot 0$ & $18 \cdot 8$ & $2 \cdot 4$ \\
\hline$P^{*}$ & & $<0.001$ & 0.593 & $<0.001$ & $<0.001$ \\
\hline \multicolumn{6}{|l|}{ Age (years) } \\
\hline $15-24$ & 1206 & $65 \cdot 8$ & $39 \cdot 6$ & $23 \cdot 6$ & $2 \cdot 6$ \\
\hline $25-34$ & 1649 & $65 \cdot 6$ & $40 \cdot 1$ & $22 \cdot 5$ & 3.0 \\
\hline $35-49$ & 908 & $66 \cdot 3$ & $43 \cdot 3$ & $20 \cdot 9$ & $2 \cdot 1$ \\
\hline$P$ & & 0.939 & 0.515 & 0.676 & 0.433 \\
\hline \multicolumn{6}{|l|}{ BMI $\left(\mathrm{kg} / \mathrm{m}^{2}\right)$} \\
\hline$<18.5$ & 322 & $77 \cdot 7$ & $37 \cdot 3$ & $28 \cdot 3$ & $2 \cdot 2$ \\
\hline $18 \cdot 5-25$ & 2860 & $76 \cdot 9$ & $41 \cdot 3$ & $22 \cdot 9$ & $2 \cdot 8$ \\
\hline$>25$ & 495 & $66 \cdot 0$ & $39 \cdot 0$ & $15 \cdot 8$ & $2 \cdot 2$ \\
\hline$P$ & & $<0.001$ & 0.004 & $<0.001$ & $0 \cdot 158$ \\
\hline \multicolumn{6}{|l|}{ Bed net use } \\
\hline Yes & 2058 & $67 \cdot 1$ & $40 \cdot 5$ & $23 \cdot 7$ & $2 \cdot 9$ \\
\hline No & 1666 & $64 \cdot 6$ & $41 \cdot 2$ & $21 \cdot 0$ & $2 \cdot 4$ \\
\hline$P$ & & $0 \cdot 131$ & 0.508 & 0.036 & 0.245 \\
\hline \multicolumn{6}{|l|}{ Household size } \\
\hline $1-4$ persons & 914 & $68 \cdot 1$ & $40 \cdot 7$ & $24 \cdot 8$ & $2 \cdot 6$ \\
\hline 5-7 persons & 1369 & $64 \cdot 7$ & $39 \cdot 6$ & $21 \cdot 7$ & $3 \cdot 4$ \\
\hline$>7$ persons & 1480 & $65 \cdot 5$ & $41 \cdot 7$ & $21 \cdot 8$ & $2 \cdot 0$ \\
\hline$P$ & & $0 \cdot 214$ & 0.444 & 0.084 & 0.081 \\
\hline \multicolumn{6}{|l|}{ Education } \\
\hline None & 3189 & $67 \cdot 7$ & $41 \cdot 2$ & $23 \cdot 7$ & $2 \cdot 8$ \\
\hline Any & 574 & $55 \cdot 6$ & $37 \cdot 6$ & $15 \cdot 9$ & $2 \cdot 1$ \\
\hline$P$ & & $<0.001$ & $<0.001$ & $<0.001$ & 0.056 \\
\hline \multicolumn{6}{|c|}{ Husband's education } \\
\hline None & 2915 & $67 \cdot 5$ & $40 \cdot 4$ & $24 \cdot 0$ & $3 \cdot 1$ \\
\hline Any & 686 & $58 \cdot 2$ & $39 \cdot 7$ & $17 \cdot 3$ & $1 \cdot 2$ \\
\hline$P$ & & $<0.001$ & 0.004 & $<0.001$ & 0.001 \\
\hline \multicolumn{6}{|l|}{ Wealth index } \\
\hline Low & 1679 & $67 \cdot 3$ & $40 \cdot 3$ & $23 \cdot 8$ & $3 \cdot 2$ \\
\hline Medium & 1521 & $68 \cdot 2$ & $41 \cdot 8$ & $24 \cdot 0$ & $2 \cdot 4$ \\
\hline High & 563 & $55 \cdot 1$ & 38.9 & $14 \cdot 4$ & $1 \cdot 8$ \\
\hline$P$ & & $<0.001$ & 0.001 & $<0.001$ & 0.025 \\
\hline \multicolumn{6}{|c|}{ Childhood place of residence } \\
\hline Urban & 749 & $57 \cdot 6$ & $39 \cdot 9$ & $16 \cdot 2$ & $1 \cdot 5$ \\
\hline Rural & 3006 & $67 \cdot 9$ & $40 \cdot 9$ & $24 \cdot 1$ & $2 \cdot 9$ \\
\hline$P$ & & $<0.001$ & 0.001 & $<0.001$ & 0.002 \\
\hline \multicolumn{6}{|c|}{ Current place of residence } \\
\hline Urban & 729 & $56 \cdot 5$ & $38 \cdot 3$ & $16 \cdot 6$ & $1 \cdot 6$ \\
\hline Rural & 3034 & $68 \cdot 1$ & $41 \cdot 3$ & $23 \cdot 9$ & $2 \cdot 9$ \\
\hline$P$ & & $<0.001$ & $<0.001$ & $<0.001$ & 0.004 \\
\hline \multicolumn{6}{|l|}{ Region } \\
\hline Kayes & 603 & $71 \cdot 1$ & $38 \cdot 6$ & $29 \cdot 0$ & 3.5 \\
\hline Koulikoro & 634 & $66 \cdot 6$ & $37 \cdot 1$ & $25 \cdot 2$ & $4 \cdot 3$ \\
\hline Sikasso & 773 & $62 \cdot 2$ & $41 \cdot 0$ & $19 \cdot 8$ & $1 \cdot 4$ \\
\hline Segou & 557 & $60 \cdot 8$ & $44 \cdot 3$ & $14 \cdot 7$ & $1 \cdot 8$ \\
\hline Mopti & 470 & $75 \cdot 3$ & $43 \cdot 4$ & $28 \cdot 3$ & $3 \cdot 6$ \\
\hline Tombouctou & 176 & $70 \cdot 4$ & $42 \cdot 0$ & $26 \cdot 1$ & $2 \cdot 3$ \\
\hline Gao & 137 & $75 \cdot 9$ & $40 \cdot 9$ & $32 \cdot 1$ & $2 \cdot 9$ \\
\hline Bamako & 392 & $54 \cdot 3$ & $39 \cdot 3$ & $13 \cdot 5$ & $1 \cdot 5$ \\
\hline$P$ & & $<0.001$ & $<0.001$ & $<0.001$ & $<0.001$ \\
\hline Total & 3763 & 65.9 & $40 \cdot 7$ & $22 \cdot 5$ & $2 \cdot 7$ \\
\hline
\end{tabular}

${ }^{*} P$ values are from tests of the association between the prevalence of different levels of anaemia and each of the variables in the table.

with those living in the capital city of Bamako $(\mathrm{OR}=2 \cdot 48$; $95 \%$ CI $1 \cdot 02,6 \cdot 04)$.

\section{Factors associated with any anaemia}

Three variables were significantly associated with any anaemia. Pregnancy was associated with any anaemia (OR $=1 \cdot 78 ; 95 \%$ CI $1 \cdot 41,2 \cdot 25$ ), but the magnitude of the association was only about half that observed for moderate- to-severe anaemia $(\mathrm{OR}=3 \cdot 75 ; 95 \% \mathrm{CI} 2 \cdot 85,4 \cdot 95)$. There was also a protective effect of overweight $(\mathrm{OR}=0 \cdot 71$; $95 \%$ CI $0.57,0.90$ for $\mathrm{BMI}>25 \mathrm{~kg} / \mathrm{m}^{2}$ ), as well as an increased risk of any anaemia among non-educated women $(\mathrm{OR}=1 \cdot 35 ; 95 \% \mathrm{CI} 1 \cdot 07,1 \cdot 70$; Table 2$)$.

Regardless of anaemia definition, three variables were not associated with anaemia, i.e. woman's age, household size and current place of residence. 
Table 2 Multilevel logistic regression modelling of risk factors for anaemia among Malian women aged 15-49 years with complete information ( $n$ 2585): data from the 2001 Mali Demographic and Health Survey

\begin{tabular}{|c|c|c|c|c|c|c|c|c|c|}
\hline \multirow[b]{2}{*}{ Variable } & \multicolumn{3}{|c|}{ Mild anaemia } & \multicolumn{3}{|c|}{ Moderate-to-severe anaemia } & \multicolumn{3}{|c|}{ Any anaemia } \\
\hline & $n$ & OR & $95 \% \mathrm{Cl}$ & $n$ & OR & $95 \% \mathrm{Cl}$ & $n$ & OR & $95 \% \mathrm{Cl}$ \\
\hline \multicolumn{10}{|l|}{ Pregnancy } \\
\hline No & 2343 & $1 \cdot 00$ & $-^{*}$ & 1742 & $1 \cdot 00$ & - & 2982 & $1 \cdot 00$ & - \\
\hline Yes & 242 & 0.96 & $0 \cdot 72,1 \cdot 28$ & 354 & $3 \cdot 75$ & $2 \cdot 85,4 \cdot 95$ & 481 & $1 \cdot 78$ & $1 \cdot 41,2 \cdot 25$ \\
\hline \multicolumn{10}{|l|}{ Age (years) } \\
\hline $15-24$ & 803 & 0.89 & $0 \cdot 70,1 \cdot 15$ & 654 & $1 \cdot 11$ & $0.82,1 \cdot 51$ & 1087 & 0.93 & $0 \cdot 74,1 \cdot 17$ \\
\hline $25-34$ & 1135 & 0.89 & $0 \cdot 72,1 \cdot 10$ & 925 & $1 \cdot 02$ & $0.79,1.33$ & 1527 & 0.93 & $0 \cdot 77,1 \cdot 13$ \\
\hline $35-49$ & 647 & 1.00 & - & 487 & 1.00 & - & 849 & 1.00 & - \\
\hline \multicolumn{10}{|l|}{ BMI $\left(\mathrm{kg} / \mathrm{m}^{2}\right)$} \\
\hline$<18 \cdot 5$ & 224 & $1 \cdot 01$ & $0 \cdot 75,1 \cdot 36$ & 202 & 1.58 & $1 \cdot 14,2 \cdot 19$ & 322 & $1 \cdot 15$ & $0.87,1.49$ \\
\hline $18 \cdot 5-25$ & 2127 & 1.00 & - & 1680 & 1.00 & - & 2860 & 1.00 & - \\
\hline$>25$ & 406 & 0.73 & $0.57,0.94$ & 302 & 0.64 & $0.47,0.89$ & 495 & $0 \cdot 71$ & $0.57,0.90$ \\
\hline \multicolumn{10}{|l|}{ Bed net use } \\
\hline Yes & 1401 & $1 \cdot 00$ & - & 1147 & 1.00 & - & 1551 & $1 \cdot 00$ & - \\
\hline No & 1184 & $1 \cdot 02$ & $0 \cdot 84,1 \cdot 23$ & 919 & 0.85 & $0 \cdot 67,1 \cdot 08$ & 1912 & 0.97 & $0 \cdot 81,1 \cdot 16$ \\
\hline \multicolumn{10}{|l|}{ Household size } \\
\hline$<5$ persons & 618 & $1 \cdot 00$ & - & 503 & $1 \cdot 00$ & - & 849 & $1 \cdot 00$ & - \\
\hline 5-7 persons & 954 & 0.87 & $0.69,1.09$ & 781 & 0.95 & $0.72,1 \cdot 25$ & 1280 & $0 \cdot 89$ & $0 \cdot 73,1 \cdot 17$ \\
\hline$>7$ persons & 1013 & $1 \cdot 03$ & $0 \cdot 80,1 \cdot 31$ & 782 & 1.04 & $0.77,1 \cdot 40$ & 1334 & $1 \cdot 01$ & $0 \cdot 81,1 \cdot 26$ \\
\hline \multicolumn{10}{|l|}{ Education level } \\
\hline Any education & 407 & 1.00 & - & 1754 & 1.00 & - & 499 & 1.00 & - \\
\hline No education & 2178 & $1 \cdot 31$ & $1 \cdot 02,1 \cdot 69$ & 312 & $1 \cdot 44$ & $1 \cdot 05,1 \cdot 97$ & 2964 & $1 \cdot 35$ & $1 \cdot 07,1 \cdot 70$ \\
\hline \multicolumn{10}{|c|}{ Husband's education level } \\
\hline Any education & 538 & $1 \cdot 00$ & - & 1666 & $1 \cdot 00$ & - & 661 & $1 \cdot 00$ & - \\
\hline No education & 2047 & $1 \cdot 11$ & $0 \cdot 88,1 \cdot 40$ & 400 & $1 \cdot 29$ & $0 \cdot 96,1 \cdot 72$ & 2802 & $1 \cdot 18$ & $0.96,1.46$ \\
\hline \multicolumn{10}{|l|}{ Wealth index } \\
\hline Low & 882 & 0.91 & $0 \cdot 70,1 \cdot 19$ & 706 & 1.07 & $0 \cdot 51,2 \cdot 24$ & 1186 & 0.99 & $0.59,1.65$ \\
\hline Medium & 818 & 0.95 & $0.73,1.22$ & 710 & $1 \cdot 46$ & $1.08,1.97$ & 1173 & $1 \cdot 11$ & $0.88,1.40$ \\
\hline High & 885 & $1 \cdot 00$ & - & 650 & $1 \cdot 00$ & - & 1104 & $1 \cdot 00$ & - \\
\hline \multicolumn{10}{|c|}{ Childhood place of residence } \\
\hline Urban & 543 & $1 \cdot 00$ & - & 396 & 1.00 & - & 659 & $1 \cdot 00$ & - \\
\hline Rural & 2042 & $1 \cdot 08$ & $0 \cdot 84,1 \cdot 39$ & 1670 & $1 \cdot 74$ & $1 \cdot 27,2 \cdot 38$ & 2804 & $1 \cdot 23$ & $0.98,1.56$ \\
\hline \multicolumn{10}{|c|}{ Current place of residence } \\
\hline Urban & 503 & $1 \cdot 00$ & - & 378 & $1 \cdot 00$ & - & 617 & $1 \cdot 00$ & - \\
\hline Rural & 2082 & $1 \cdot 41$ & $0 \cdot 93,2 \cdot 14$ & 1688 & $1 \cdot 03$ & $0 \cdot 62,1 \cdot 71$ & 2846 & $1 \cdot 22$ & $0 \cdot 84,1 \cdot 80$ \\
\hline \multicolumn{10}{|l|}{ Region } \\
\hline Bamako & 279 & $1 \cdot 00$ & - & 193 & $1 \cdot 00$ & - & 326 & $1 \cdot 00$ & - \\
\hline Kayes & 365 & $0 \cdot 86$ & $0.50,1.48$ & 344 & $1 \cdot 89$ & $0.96,3.73$ & 544 & $1 \cdot 13$ & $0.69,1.86$ \\
\hline Koulikoro & 414 & 0.78 & $0.44,1.36$ & 378 & 1.57 & $0 \cdot 77,3 \cdot 22$ & 596 & 0.98 & $0.59,1.65$ \\
\hline Sikasso & 584 & 0.69 & $0 \cdot 40,1 \cdot 18$ & 438 & 0.72 & $0.35,1.47$ & 742 & $0 \cdot 72$ & $0.43,1 \cdot 19$ \\
\hline Segou & 439 & 0.73 & $0 \cdot 42,1 \cdot 28$ & 292 & 0.52 & $0.25,1.09$ & 519 & 0.63 & $0.37,1.07$ \\
\hline Mopti & 307 & $1 \cdot 28$ & $0 \cdot 72,2 \cdot 28$ & 251 & $1 \cdot 68$ & $0.79,3.54$ & 446 & $1 \cdot 37$ & $0 \cdot 81,2 \cdot 35$ \\
\hline Tombouctou & 114 & 1.06 & $0 \cdot 53,2 \cdot 10$ & 92 & 1.65 & $0 \cdot 71,3 \cdot 84$ & 160 & $1 \cdot 31$ & $0.69,2.47$ \\
\hline Gao & 83 & $1 \cdot 36$ & $0 \cdot 66,2 \cdot 80$ & 78 & $2 \cdot 48$ & $1 \cdot 02,6 \cdot 04$ & 130 & 1.55 & $0.79,3.06$ \\
\hline
\end{tabular}

${ }^{*} 95 \% \mathrm{Cl}$ not calculated; reference category.

\section{Contribution of contextual effects to moderate- to-severe anaemia prevalence}

The contribution of community effects was derived from the null model, which is the model containing only the outcome and a constant (no explanatory variable). Table 3 shows that $13 \%$ of the variability in risk of mild anaemia in Malian women was attributable to the difference between communities. These differences between communities accounted for $14 \%$ in the risk of any anaemia and $20 \%$ for moderate-to-severe anaemia.

\section{Discussion}

The present analysis shows that two-thirds of non-pregnant women and three-quarters of pregnant women in
Mali were anaemic. Prevalence of anaemia was 10\% higher than the mean anaemia prevalence in other subSaharan African countries where comparable nationally representative data are available (Table 4). The level of clustering found in the present study is comparable to what we found in previous research on multilevel determinants of anaemia among children in Benin and Mali ${ }^{(32)}$. This means that the risk of anaemia is mostly attributable to individual and household patterns (approximately $80 \%$ ) rather than to differences between communities.

Among the eleven variables included in the present models, two were associated with mild anaemia, six with moderate-to-severe anaemia and three with any anaemia. When mild anaemia was combined with moderate-to-severe anaemia as is usually done in anaemia-related research, three key factors associated with moderate-to-severe 
Table 3 Variance estimates (and their standard errors) from the two-level binomial logit models for mild anaemia, moderate-to-severe anaemia and any anaemia among Malian women aged 15-49 years: data from the 2001 Mali Demographic and Health Survey

\begin{tabular}{|c|c|c|c|c|c|c|}
\hline & \multicolumn{2}{|c|}{ Mild anaemia } & \multicolumn{2}{|c|}{ Moderate-to-severe-anaemia } & \multicolumn{2}{|c|}{ Any anaemia } \\
\hline & Variance estimate & SE & Variance estimate & SE & Variance estimate & SE \\
\hline $\begin{array}{l}\text { Level 2: Community } \\
\text { VPC }\end{array}$ & $\begin{array}{l}0.499 \\
13.04\end{array}$ & 0.077 & $\begin{array}{ll}0.818 & \\
& 19 \cdot 79\end{array}$ & $0 \cdot 114$ & $\begin{array}{l}0.538 \\
13.78\end{array}$ & 0.076 \\
\hline
\end{tabular}

VPC, variance partition coefficient.

All variance variables were significant at the 0.001 level.

Table 4 Prevalence of anaemia in women from sub-Saharan African countries: data are from recent Demographic Health Surveys

\begin{tabular}{|c|c|c|c|c|c|c|c|c|}
\hline & \multicolumn{8}{|c|}{ Prevalence of anaemia (\%) } \\
\hline & \multicolumn{4}{|c|}{ Pregnant } & \multicolumn{4}{|c|}{ Non-pregnant } \\
\hline & Mild & Moderate & Severe & Any & Mild & Moderate & Severe & Any \\
\hline Benin (2001) & $24 \cdot 7$ & $43 \cdot 3$ & $4 \cdot 7$ & $72 \cdot 7$ & $40 \cdot 7$ & $21 \cdot 8$ & $1 \cdot 8$ & $64 \cdot 3$ \\
\hline Burkina Faso (2003) & $30 \cdot 6$ & $35 \cdot 4$ & $2 \cdot 3$ & $68 \cdot 3$ & $37 \cdot 8$ & $14 \cdot 7$ & $1 \cdot 1$ & $53 \cdot 7$ \\
\hline Cameroon (2004) & $18 \cdot 8$ & $31 \cdot 4$ & $0 \cdot 7$ & $50 \cdot 9$ & $32 \cdot 5$ & $11 \cdot 6$ & 0.9 & $44 \cdot 9$ \\
\hline Ghana (2003) & $33 \cdot 2$ & $26 \cdot 7$ & $1 \cdot 2$ & $61 \cdot 1$ & $34 \cdot 8$ & $9 \cdot 0$ & $0 \cdot 8$ & $44 \cdot 6$ \\
\hline Madagascar (2003-4) & $20 \cdot 9$ & $27 \cdot 7$ & 1.5 & $50 \cdot 1$ & $34 \cdot 6$ & $8 \cdot 5$ & $2 \cdot 9$ & $46 \cdot 0$ \\
\hline Mali (2001) & $24 \cdot 5$ & $43 \cdot 6$ & $5 \cdot 2$ & $73 \cdot 4$ & $39 \cdot 3$ & $20 \cdot 8$ & $2 \cdot 8$ & $62 \cdot 9$ \\
\hline Tanzania (2004) & $22 \cdot 7$ & $32 \cdot 8$ & $2 \cdot 7$ & $58 \cdot 2$ & $32 \cdot 6$ & $14 \cdot 5$ & $1 \cdot 2$ & $48 \cdot 4$ \\
\hline Uganda (2000-1) & $22 \cdot 1$ & $17 \cdot 1$ & $2 \cdot 0$ & $41 \cdot 2$ & $22 \cdot 1$ & $7 \cdot 5$ & $0 \cdot 7$ & $30 \cdot 4$ \\
\hline
\end{tabular}

anaemia were non-significant - SES, childhood place of residence, region of residence - and the magnitude of association with the three remaining risk factors - pregnancy, BMI, education - was diluted.

There was no association between pregnancy and mild anaemia in the present study, but pregnant women were four times more at risk of moderate-to-severe anaemia. However, anaemia prevalence was over $60 \%$ among nonpregnant women, which means that most women are already anaemic before pregnancy. Because of the increase in Fe needs during pregnancy, it is likely that non-anaemic women and mildly anaemic women shift to moderate and severe anaemia(33). This does not fully explain the lack of association between mild anaemia and pregnancy in multilevel analysis however, since 25\% of pregnant women had mild anaemia and a similar proportion was non-anaemic.

The physical and socio-cultural characteristics of a woman's childhood place of residence have an influence on her current health and nutrition behaviours during adulthood $^{(34)}$. Moreover, beliefs and attitudes developed while women are living in urban or rural areas during childhood may potentially impact parenting practices during adulthood ${ }^{(35)}$. The current study reveals that the prevalence of severe anaemia was two times higher among these women from rural settings. This association disappeared in multilevel modelling; however, the results suggest that more research should focus on the real impact of the childhood environment on women's health.

Among the various risks factors we studied, one deserves particular attention. Women with BMI $>25 \mathrm{~kg} / \mathrm{m}^{2}$ appeared at lower risk of anaemia, which could suggest that having a diet providing sufficient energy to maintain body weight within normal limits does not suffice in supplying Fe. Furthermore, as energy intake became insufficient and BMI fell below $18.5 \mathrm{~kg} / \mathrm{m}^{2}$, the risk of being moderately to severely anaemic increased. However, other studies in different context have recently reported a higher risk of anaemia among obese women ${ }^{(36,37)}$. This overall association between BMI and risk of anaemia appears to point towards the need to develop interventions to increase available $\mathrm{Fe}$ in the diet of the whole population, interventions that will have to consider limits that appear to be associated with the absence of formal education in the majority of Malian women.

The most common cause of anaemia during pregnancy among sub-Saharan Africans is inadequate diet and insufficient supply of prenatal Fe and folate supplement. However, infections, notably malaria and HIV/AIDS, are other causes of anaemia in non-pregnant and pregnant women in sub-Saharan Africa. In the present study, use of bed nets (used as a proxy for malaria infection) did not show any association with anaemia. However, previous studies have demonstrated that malaria is the second leading cause of anaemia in Mali after Fe deficiency ${ }^{(9)}$. In a former study in Malawi, elevated concentrations of C-reactive protein, an indicator of infection, were found in 54\% of anaemic women with no nutritional deficiencies ${ }^{(38)}$.

HIV infection increases one's risk of anaemia ${ }^{(39)}$. Furthermore, HIV-positive women who are also infected with malaria are more likely to be anaemic than HIVnegative women ${ }^{(40)}$. However, the HIV infection rate among women in Mali of $1.7 \%$ is relatively low compared with other countries in sub-Saharan Africa ${ }^{(41,42)}$. For this 
reason, it is likely that HIV will be only a minor contributor to anaemia prevalence in Mali.

On the other hand, results of Fe-based interventions to fight anaemia in sub-Saharan Africa have been mitigated and their failure often attributed to poor compliance, limited duration of intervention and lack of infrastructure $^{(43,44)}$. Rarely has the possibility that the cut-off point for defining anaemia might be inappropriate been considered as a potential cause of the absence of impact. George Beaton made a similar point during the 2001 meeting of the International Nutritional Anemia Consultative Group, with the hypothesis that the 'failure' of interventions might be due to the 'inappropriate and unnecessary high' cut-off for anaemia, at least during pregnancy ${ }^{(45)}$. Some researchers have suggested lowering the cut-off for anaemia among people from African origin by $1 \mathrm{~g} / \mathrm{dl}$, which would mean a mathematical eradication of mild anaemia in its current definition ${ }^{(46-48)}$. Comparable studies have not been completed among African women living in Africa, but one can reasonably anticipate similar results. Our results would tend to support lowering the cut-off point for anaemia to $10 \mathrm{~g} / \mathrm{dl}$ because well-known risk factors for anaemia (pregnancy, low SES, community environment) do not show any association with mild anaemia whereas they show very strong and significant association with moderate-to-severe anaemia. However, a recent literature review showed that not only severe anaemia but also mild anaemia has health consequences among women ${ }^{(1,49)}$.

Therefore, if mild anaemia needs to be addressed, it might require different strategies from those for moderate-to-severe anaemia. Increasing available dietary $\mathrm{Fe}$ could be particularly successful against mild anaemia, while addressing moderate-to-severe anaemia would require working more on health services and underlying socio-economic factors responsible for malnutrition and multiple constraints to health. While much research is obviously required if any progress against anaemia is to be made, this should include further identification of the risk factors associated with mild anaemia.

\section{Acknowledgements}

I.N.-T., O.R. and B.K.-D. participated in designing the study and analysing and interpreting the data. I.N.-T. wrote the first draft of the paper. All researchers contributed to the preparation of and approved the paper. This work was partly funded by a scholarship from the Mellon Foundation. The authors declare no conflicts of interest.

\section{References}

1. Stoltzfus RJ (2003) Iron deficiency: global prevalence and consequences. Food Nutr Bull 24, 4 Suppl., S99-S103.

2. Stoltzfus RJ (2001) Iron-deficiency anemia: reexamining the nature and magnitude of the public health problem.
Summary: implications for research and programs. J Nutr 131, 2 Suppl. 2, 697S-700S.

3. Allen LH (1997) Pregnancy and iron deficiency: unresolved issues. Nutr Rev 55, 91-101.

4. Untoro J, Gross R, Schultink W \& Sediaoetama D (1998) The association between BMI and haemoglobin and work productivity among Indonesian female factory workers. Eur J Clin Nutr 52, 131-135.

5. Haas JD \& Brownlie T (2001) Iron deficiency and reduced work capacity: a critical review of the research to determine a causal relationship. J Nutr 131, 2 Suppl. 2, 676S-688S

6. Stoltzfus RJ (1997) Rethinking anaemia surveillance. Lancet 349, 1764-1766.

7. Brabin BJ, Premji Z \& Verhoeff F (2001) An analysis of anemia and child mortality. J Nutr 131, 2 Suppl. 2, 636S-645S

8. Scholl TO, Hediger ML, Fischer RL \& Shearer JW (1992) Anemia vs iron deficiency: increased risk of preterm delivery in a prospective study. Am J Clin Nutr 55, 985-988.

9. Ayoya MA, Spiekermann-Brouwer GM, Traore AK, Stoltzfus RJ \& Garza C (2006) Determinants of anemia among pregnant women in Mali. Food Nutr Bull 27, 3-11.

10. Bouvier P, Doumbo O, Breslow N, Robert CF, Mauris A, Picquet M, Kouriba B, Dembele HK, Delley V \& Rougemont A (1997) Seasonality, malaria, and impact of prophylaxis in a West African village I. Effect of anemia in pregnancy. Am J Trop Med Hyg 56, 378-383.

11. Kayentao K, Mungai M, Parise M, Kodio M, Keita AS, Coulibaly D, Maiga B, Traoré B \& Doumbo OK (2007) Assessing malaria burden during pregnancy in Mali. Acta Trop 102, 106-112.

12. Aguayo VM, Kone D, Bamba SI, Diallo B, Sidibé Y, Traoré D, Signé P \& Baker SK (2005) Acceptability of multiple micronutrient supplements by pregnant and lactating women in Mali. Public Health Nutr 8, 33-37.

13. Dicko A, Klion AD, Thera MA et al. The etiology of severe anemia in a village and a periurban area in Mali. Blood 104, 1198-1200.

14. Dicko A, Mantel C, Thera MA, Doumbia S, Diallo M, Diakité M, Sagara I \& Doumbo OK (2003) Risk factors for malaria infection and anemia for pregnant women in the Sahel area of Bandiagara, Mali. Acta Trop 89, 17-23.

15. Kreft IG (1998) An illustration of item homogeneity scaling and multilevel analysis techniques in the evaluation of drug prevention programs. Eval Rev 22, 46-77.

16. Macro International (1996) DHS Sampling Manual. Calverton, MD: Macro International.

17. Cellule de la Planification et de la Statistique du Ministère de la Santé \& ORC Macro (2002) Enquête Démographique et de Santé au Mali, 2001. Calverton, MD: CPS/MS and ORC Macro.

18. Morris SS, Ruel MT, Cohen RJ, Dewey KG, de la Briere B \& Hassan MN (1999) Precision, accuracy, and reliability of hemoglobin assessment with use of capillary blood. Am J Clin Nutr 69, 1243-1248.

19. Boulton FE, Nightingale MJ \& Reynolds W (1994) Improved strategy for screening prospective blood donors for anaemia. Transfus Med 4, 221-225.

20. Sharman A (2000) Anemia Testing in Population-based Surveys: General Information and Guidelines for Country Monitors and Program Managers. Calverton, MD: ORC Macro.

21. World Health Organization (1968) The prevalence of iron deficiency anemia. Nutr Rev 26, 263-265.

22. World Health Organization/UNICEF/United Nations University (2001) Iron Deficiency Anemia: Assessment, Prevention, and Control. WHO/NHD/01.3. Geneva: WHO.

23. World Health Organization (1995) Iron Deficiency Anemia Through Primary Health Care: A Guide for Health 
Administrators and Programme Managers. WHO-EM/NUT/ 177, $E / G / 11.96$. Geneva: WHO.

24. Rutstein SO \& Kiersten J (2004) The DHS Wealth Index. Calverton, MD: ORC Macro.

25. Snjjders T \& Bosker RJ (1999) Multilevel Analysis: An Introduction to Basic and Advanced Multilevel Modelling. London: Sage Publishers.

26. Greenland S (2000) Principles of multilevel modelling. Int J Epidemiol 29, 158-167.

27. Zunzunegui MV, Garcia de Yebenes MJ, Forster M, Aguilar Conesa MD, Rodriguez Laso A \& Otero A (2004) Multilevel model applications to the analysis of longitudinal data. Rev Esp Salud Publica 78, 177-188.

28. Moerbeek M, van Breukelen GJ \& Berger MP (2003) A comparison between traditional methods and multilevel regression for the analysis of multicenter intervention studies. J Clin Epidemiol 56, 341-350.

29. Goldstein H, Browne W \& Rasbash J (2002) Multilevel modelling of medical data. Stat Med 21, 3291-3315.

30. Merlo J, Chaix B, Yang M, Lynch J \& Rastam L (2005) A brief conceptual tutorial of multilevel analysis in social epidemiology: linking the statistical concept of clustering to the idea of contextual phenomenon. J Epidemiol Community Health 59, 443-449.

31. Rasbash J, Steele F, Browne WJ \& Prosser B (2004) A User's Guide to MLwiN Version 2.0. London: London Institute of Education.

32. Ngnie-Teta I, Kuate-Defo B \& Receveur O (2007) Risk factors of moderate-to-severe anemia among children in Benin and Mali: insights from a multilevel analysis. Food Nutr Bull 28, 76-89.

33. De Leeuw NK, Lowenstein L \& Hsieh YS (1966) Iron deficiency and hydremia in normal pregnancy. Medicine (Baltimore) 45, 291-315.

34. Uyanga J (1980) Rural-urban differences in child care and breastfeeding behaviour in southeastern Nigeria. Soc Sci Med 14, 23-29.

35. United Nations (1985) Socio-economic Differentials in Child Mortality in Developing Countries. New York: UN Department of International Economics and Social Affairs.

36. Eckhardt CL, Torheim LE, Monterrubio E, Barquera S \& Ruel MT (2008) The overlap of overweight and anaemia among women in three countries undergoing the nutrition transition. Eur J Clin Nutr 62, 238-246.

37. Nead KG, Halterman JS, Kaczorowski JM, Auinger P \& Weitzman M (2004) Overweight children and adolescents: a risk group for iron deficiency. Pediatrics 114, 104-108.
38. van den Broek NR, White SA, Flowers C, Cook JD, Letsky EA, Tanumihardjo SA, Mhango C, Molyneux M \& Neilson JP (2006) Randomised trial of vitamin A supplementation in pregnant women in rural Malawi found to be anaemic on screening by HemoCue. BJOG 113, 569-576.

39. Sullivan PS, Hanson DL, Chu SY, Jones JL, Ward JW \& Adult/Adolescent Spectrum of Disease Group (1998) Epidemiology of anemia in human immunodeficiency virus (HIV)-infected persons: results from the Multistate Adult and Adolescent Spectrum of HIV Disease Surveillance Project. Blood 91, 301-308.

40. Brentlinger PE, Behrens CB \& Micek MA (2006) Challenges in the concurrent management of malaria and HIV in pregnancy in sub-Saharan Africa. Lancet Infect Dis 6, 100-111.

41. Joint United Nations Programme on HIV/AIDS, Population Reference Bureau (2003) ISBS 2003. Sentinel Surveillance. Geneva: UNAIDS.

42. Joint United Nations Programme on HIV/AIDS (2006) 2006 Report on the Global AIDS Epidemic. Geneva: UNAIDS.

43. Sloan NL, Jordan E \& Winikoff B (2002) Effects of iron supplementation on maternal hematologic status in pregnancy. Am J Public Health 92, 288-293.

44. Galloway R \& McGuire J (1994) Determinants of compliance with iron supplementation: supplies, side effects, or psychology? Soc Sci Med 39, 381-390.

45. International Nutritional Anemia Consultative Group \& US Agency for International Development (2002) Why Iron Is Important and What to Do About It: A New Perspective. Washington, DC: ILSI.

46. Yip R, Schwartz S \& Deinard AS (1984) Hematocrit values in white, black, and American Indian children with comparable iron status. Evidence to support uniform diagnostic criteria for anemia among all races. Am J Dis Child 138, 824-827.

47. Earl R \& Woteki CE (editors) (1993) Iron Deficiency Anemia: Recommended Guidelines for the Prevention, Detection, and Management among US Children and Women of Childbearing Age. Washington, DC: National Academy Press.

48. Johnson-Spear MA \& Yip R (1994) Hemoglobin difference between black and white women with comparable iron status: justification for race-specific anemia criteria. Am J Clin Nutr 60, 117-121.

49. Stoltzfus R, Mullany L \& Black R (2003) Iron deficiency anaemia. In Comparative Quantification of Health Risks: Global and Regional Burden of Disease due to Selected Major Risk Factors, pp. 163-209. Geneva: WHO. 